\title{
Paisagem e uso comum da Floresta Ombrófila Mista pela população cabocla do oeste de Santa Catarina
}

\author{
Marlon Brandt
}

\section{SciELO Books / SciELO Livros / SciELO Libros}

BRANDT, M. Paisagem e uso comum da Floresta Ombrófila Mista pela população cabocla do oeste de Santa Catarina. In: GERHARDT, M., NODARI, E.S., and MORETTO, S.P., eds. História ambiental e migrações: diálogos [online]. São Leopoldo: Oikos; editora UFFS, 2017, pp. 123-138. ISBN: 978-85-64905-68-9. https://doi.org/10.7476/9788564905689.0009.

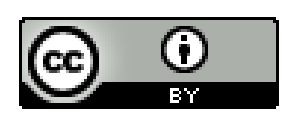

All the contents of this work, except where otherwise noted, is licensed under a Creative Commons Attribution 4.0 International license.

Todo o conteúdo deste trabalho, exceto quando houver ressalva, é publicado sob a licença Creative Commons Atribição 4.0.

Todo el contenido de esta obra, excepto donde se indique lo contrario, está bajo licencia de la licencia $\underline{\text { Creative Commons }}$ $\underline{\text { Reconocimento 4.0. }}$. 


\section{Paisagem e uso comum da Floresta Ombrófila Mista pela população cabocla do oeste de Santa Catarina}

Marlon Brandt

\section{Introdução}

Este texto tem por objetivo discutir o uso comum da terra pela população cabocla e como essa prática modelou a paisagem dos espaços dominados pela Floresta Ombrófila Mista do Oeste de Santa Catarina entre a metade do século XIX e a primeira metade do século XX. Procura-se demonstrar que práticas como a extração da erva-mate e a criação de animais em comum, além de conservar morfologicamente a paisagem florestal, eram costumeiras e uma importante fonte de renda para diversas famílias caboclas da região. O termo "caboclo" neste texto baseia-se no emprego dado por Paulo Pinheiro Machado (2004, p. 48) que utiliza a palavra com o mesmo sentido dado "pelos habitantes do planalto, ou seja, o habitante pobre do meio rural". Embora, conforme o autor, "não haja uma conotação étnica nesta palavra, frequentemente o caboclo era mestiço, muitas vezes negro. Mas a principal característica desta palavra é que distingue uma condição social e cultural, ou seja, são caboclos os homens pobres, pequenos lavradores posseiros, agregados ou peões".

Práticas relacionadas ao usufruto em comum da terra e dos recursos naturais implantados por comunidades para a geração de benefícios mútuos e o manejo de recursos disseminaram-se em diversos espaços no planeta. É provável que muitas formas tenham desaparecido ou assumido novas feições, como apontam Margaret McKean e Elinor Ostrom (2001, p. 87), "na medida em que as comunidades tradicionais optaram por outras relações ambientais, particularmente à luz de mudanças tecnológicas”. Em muitos casos esses regimes sofreram e vêm sofrendo com a legislação, que desconsidera essa forma de regime de propriedade ou uso da terra, além da interferência ou inserção de pessoas externas a uma determinada comunidade 
BRANDT, M. • Paisagem e uso comum da Floresta Ombrófila Mista pela população cabocla...

ou região. Estes elementos, ao se apropriarem daquele espaço, promovem, na quase totalidade dos casos, a desarticulação das redes sociais do lugar, seja pelo cercamento, destruição ambiental ou pela própria expropriação dos moradores, culminando não apenas no declínio ou mesmo término do usufruto em comum da terra, mas também de outras práticas sociais de cunho coletivo.

No Brasil são inúmeros os exemplos de áreas de uso comum, e é vasta a sua distribuição espacial, cujo uso, conforme Alfredo Wagner Berno de Almeida (2004, p. 12), aparece "combinado tanto com a propriedade quanto com a posse, de maneira perene ou temporária", podendo ser encontrados em comunidades não urbanas e urbanas, e se caracterizam pelo usufruto em comum de recursos como peixes, plantas medicinais, produtos do extrativismo vegetal e atividades relacionadas à criação de animais (DIEGUES, 2001). Verifica-se nesses espaços a existência de uma rede complexa de elementos naturais e humanos, cuja interação se reflete na paisagem. Esta, vista como a materialização da ação humana ao longo do tempo, detém não somente uma dimensão espacial, mas também histórica, entendida como o resultado da acumulação de atividades que expressam uma imbricada relação que envolve diferentes objetos e ações em variadas escalas temporais (SANTOS, 2004, 2006). Analisar a construção de uma paisagem implica, contudo, não apenas descrever o ambiente e os modos de vida de suas populações, mas também, como destaca Paul Claval (2004, p. 70-71), compreender "as relações complexas que se estabelecem entre os indivíduos e os grupos, o ambiente que eles transformam, as identidades que ali nascem ou se desenvolvem", pois, "o mundo que nós estudamos é moldado pela ação dos homens e se encontra marcado por seus saberes, seus desejos e aspirações".

Serão abordados nesse capítulo três importantes períodos históricogeográficos da trajetória da população cabocla na região para compreender sua relação com a floresta e suas práticas de uso comum. Em ordem cronológica, o primeiro foi o processo de interiorização do povoamento, rumo às florestas do oeste catarinense a partir do século XIX, construindo uma paisagem baseada em um modelo sociocultural de adaptação ao meio, desenvolvendo atividades relacionadas a agricultura de subsistência, atividades extrativistas e de criação. O segundo capítulo aborda as diferenciações dentro da Floresta Ombrófila Mista em relação a sua composição vegetal e de que forma ela promoveu diferenciações espaciais na ocupação e no uso de 
seus recursos naturais, analisando a extração da erva-mate e a criação de animais. A terceira parte propõe discutir como o processo de transformações nessa paisagem, a partir das primeiras duas décadas do século XX, promovidas pela apropriação privada da terra, a colonização e o aporte de madeireiras levaram a uma série de rupturas e ao término das práticas de uso e acesso em comum da floresta na região.

\section{Povoamento das florestas às margens das fazendas dos campos}

Até a chegada dos europeus, a região era ocupada por grupos indígenas dos grupos Kaigang, Xokleng e Guarani, quando então passou a ser alvo de incursões de jesuítas e, mais tarde, de bandeirantes provenientes da província de São Paulo à procura de alguma forma de riqueza, incluindo a escravização dos indígenas. Essa paisagem passou a ser modificada pela ação do homem, principalmente com a ocupação portuguesa na primeira metade do século XVIII, que marcou a formação das primeiras fazendas pastoris nas áreas de campos e a abertura dos caminhos de tropas destinados ao transporte de gado muar, bovino e cavalar, interligando por terra o Rio Grande do Sul ao sudeste e às regiões mineradoras.

Dominava nos campos sulinos uma economia de caráter pastoril, com baixa ocupação demográfica, em que a ação humana na paisagem se fazia perceber principalmente pela presença de rebanhos nas áreas de campos. As vastas formações de floresta que cercavam os campos consistiam em um espaço inadequado para as atividades econômicas predominantes, pois impedia "a maior extensão das áreas de campo, e portanto, de alimento para o gado" (LAGO, 1988, p. 264).

Essas florestas, às margens das propriedades pastoris, surgiram assim como um espaço possível de ocupação, principalmente a partir do final da primeira metade do século XIX, quando as principais áreas de campos já haviam sido apropriadas para a criação de gado, contribuindo, nas palavras de Paulo Pinheiro Machado (2004, p. 355), "para a maior presença social de posseiros e sitiantes independentes". A posse surgiu como uma forma extralegal de acesso à terra ainda no período colonial, quando o acesso oficial a estas ocorria a partir da concessão de sesmarias. De acordo com Emília Viotti da Costa (1999, p. 175), "todas as pessoas que penetravam nas regiões do interior - áreas sem nenhum valor comercial - podiam controlar um pedaço de terra, desde que fossem capazes de enfrentar os índios 
e sobreviverem na selva". Assim, para a autora, "a disponibilidade de grandes extensões de terra tornou-a acessível àqueles que não tinham condições de participar da economia comercial, permitindo-lhes sobreviver no âmbito da economia de subsistência" (COSTA, 1999, p. 175).

Como agentes dessa expansão espacial, é possível incluir ex-escravos, negros libertos, foragidos da justiça, ex-agregados, peões e descendentes de fazendeiros em busca de novas terras. Partiam principalmente das grandes áreas de fazendas de criação, situadas, ao leste, nos campos de Lages, Curitibanos e Campos Novos, enquanto por parte do Paraná provinham dos Campos Gerais, de Guarapuava e de Palmas. A instabilidade política do Rio Grande do Sul, principalmente nos anos da Revolução Farroupilha (1835-1845) e da Revolução Federalista (1893) trouxe um acréscimo a este contingente populacional, ocupando não apenas os campos, mas também as florestas, mais ao norte (AURAS, 2001). No oeste catarinense, a extração da erva-mate, que ocorria desde o final do século XIX, teria também atraído não apenas moradores de origem brasileira, mas também famílias provenientes da Argentina e do Paraguai (PARANÁ, 1899; CORRÊA, 1970).

Nesse cenário de ocupação, campos e florestas representavam não apenas paisagens distintas, mas também diferentes modos de vida e possibilidades de independência dos laços até então costurados com as fazendas das áreas de campos. Autores como Rinaldo Arruda (1999) destacam que o modo de povoamento empreendido pelos portugueses no Brasil ao longo do período colonial foi um dos responsáveis pela formação de um modelo sociocultural de adaptação ao meio, em que tanto sua ocupação quanto a utilização dos recursos naturais se devem às influências indígenas, às quais se incluem mais tarde também as heranças africanas e o caráter cíclico e irregular do povoamento. Isso pode ser também visto no oeste catarinense. As sucessivas levas populacionais passaram a adotar, ressignificar e construir práticas sociais e espaciais condizentes com o meio, desenvolvendo o conhecimento sobre o funcionamento de seu ecossistema e a utilização dos recursos encontrados em áreas como as de domínio da Floresta Ombrófila Mista. Essas podem ser encontradas em práticas como a caça, a pesca a agricultura de subsistência, a extração da erva-mate e a criação de animais "à solta". 


\section{Extração da erva-mate e criação de animais "à solta"}

A Floresta Ombrófila Mista, popularmente conhecida como Floresta de Araucária, Mata de Araucária ou Mata dos Pinhais dentre outras denominações, dada a presença dominante da araucária (Araucaria angustifolia) na fisionomia da paisagem, vista de cima pode parecer homogênea. Porém esta apresenta subformações e submatas com diferentes espécies que assumem maior ou menor presença em algumas áreas, relacionadas a aspectos como clima e relevo. Encontram-se, além da araucária, diversas espécies de lauráceas, mirtáceas e aquifoliáceas como a erva-mate (Ilex paraguariensis), formando assim dois grupos distintos de comunidades como araucárias e lauráceas, como apontam Pedro Furtado Leite e Roberto Miguel Klein (1990). Na primeira, que parte do Planalto Norte, alto Vale do Rio do Peixe rumo ao oeste, a araucária se distribui de forma esparsa em um bosque composto por cerca de 70 a $90 \%$ de árvores pertencentes a espécies como a imbuia (Ocotea porosa), sendo essa a espécie mais representativa, além de outras, como a canela-amarela (Nectandra lanceolata), canelapreta (Nectandra megapotâmica), canela-fogo ou canela-pururuca (Cryptocarya aschersoniana) acompanhada de espécies como a sacopema (Sloanela monosperma), guabirobeira (Campomanesia xanthocarpa) e a erva-mate (Ilex paraguariensis). No outro grupo, localizado entre a parte sul do Vale do Rio do Peixe e ao leste na região do município de Lages, a araucária forma um estrato superior bastante denso, sobre um estrato de 60 a $80 \%$ de espécies como a canela-lageana (Ocotea pulchella), espécie dominante, canela-amarela (Nectandra lanceolata), canela-guaicá (Ocotea puberula), canela-fedida (Nectandra grandiflora), guabirobeira (Campomanesia xanthocarpa) e diversas mirtáceas e aquifoliáceas.

Essas diferenças encontradas dentro de uma mesma formação vegetal influenciaram na natureza de ocupação e nos diferentes usos dos seus recursos naturais, como ressaltou, por exemplo, Maurício Vinhas de Queiroz (1981, p. 32) ao descrever a paisagem e os modos de vida da população cabocla em seu estudo sobre a Guerra do Contestado (1912-1916): "[se] os campos nativos marcam as superfícies por onde se estendeu a frente pastoril, os trechos de floresta indicam aquelas por onde se espalhou a atividade extrativa".

A produção ervateira, que até meados do século XX seguia o modelo indígena, era realizada normalmente nos meses de inverno, quando todo o 
trabalho dependia somente da força familiar, em que poderia ocorrer a exploração em comum dos vastos ervais encontrados em terras devolutas (BRANDT; SILVA, 2014). A erva-mate seria inclusive moeda corrente, vendida a comerciantes locais, muitos deles argentinos - alguns dos quais também ervateiros -, na base da troca por gêneros alimentícios e outros produtos de consumo não produzidos nas suas terras, como tecidos, sal açúcar, café, pólvora, dentre outros. Moradores locais poderiam também ser assalariados ou tarefeiros na coleta da erva-mate para diversas companhias ervateiras que se instalaram na região fronteiriça a partir da segunda metade do século XIX (FERRARI, 2011).

A produção tinha destinos variados, dependendo de sua localização. Nas áreas mais ao oeste, o destino eram as empresas argentinas localizadas na fronteira e comerciantes locais ou filiais de ervateiras paranaenses localizadas na região de Porto União. De lá o produto poderia seguir, via estrada de ferro, aos portos do Paraná e de Santa Catarina. A construção e operação, na primeira década do século XX, da Estrada de Ferro São PauloRio Grande, cujo traçado seguia o rumo do Rio do Peixe, dinamizou a produção ervateira nas áreas próximas, atraindo ervateiros interessados em explorar as terras, e comerciantes que despachavam o produto, tendo como destino os países do Prata e o Rio Grande do Sul (PARANÁ, 1899; CORREA, 1970; GOULARTI FILHO, 2012).

Essa exploração ervateira na região, realizada tanto por caboclos que viviam nas florestas quanto por companhias ervateiras, seria um dos fatores que contribuíram para o assentamento mais efetivo da população na região, principalmente na fronteira com a Argentina, então principal mercado consumidor. Desse fluxo surgiram núcleos de povoamento como Dionísio Cerqueira, em Santa Catarina, Barracão e Santo Antônio do Sudeste, no Paraná, ainda em fins do século XIX (FERRARI, 2011).

Nas florestas onde a erva-mate escasseava, era a criação que assumia o papel de principal fonte de renda. Nesses espaços, Vinhas de Queiroz (1981, p. 35) menciona que "onde quer que fossem raras as minas de erval", era a "roça cabocla" que substituía o aproveitamento da erva-mate, sendo, em outros lugares, complemento das atividades extrativas, fato também apontado por Roberto Lobato Corrêa (1970) em relação ao sudoeste do Paraná. Era a "roça cabocla" formada, de acordo com Arlene Renk (2006, p. 107), a partir da adoção de "uma prática costumeira de dividir as terras em terras de plantar e terras de criar". 
Nas áreas que compunham as "terras de plantar", ocorria uma policultura com rotação de terras que, conforme Vinhas de Queiroz (1981, p. 36), estabelecia no milho "o centro da lavoura, consorciado ao feijão e por vezes à abóbora e à melancia". Cultivavam, sob o sistema de rotação de terras, formando a roça após derrubarem e queimarem parte da floresta. Essa técnica, conhecida como coivara, quando praticada em amplas áreas de terras, com baixa densidade demográfica, permitindo assim a possibilidade de amplos intervalos de descanso da floresta, representa, conforme Emilio Moran (2009, p. 21), "um método sensato e barato para obter produtos vitais", pois, por ser praticado em pequenas dimensões, permitia uma recomposição mais fácil do solo pela absorção de suas cinzas. $\mathrm{Na}$ "roça cabocla" eram cercados não os espaços de criação, mas "terras de plantar", para evitar a invasão de animais. Após a abertura da roça, esta poderia ser cercada com tábuas lascadas de pinheiros, os chamados rachões, trincheiras abertas ao solo ou mesmo araucárias que, derrubadas, fechavam o perímetro das roças (BRANDT, 2015).

Já as "terras de criar" abrangiam o restante das terras. Enquanto o bovino era criado nas áreas abertas, o suíno vivia nas florestas, sendo a principal criação de muitas famílias. A criação de suínos era comum no Brasil desde o período colonial. Warren Dean (2004) argumenta que essa forma de criação possivelmente era a responsável pela conservação e/ou disseminação da vegetação florestal, embora pudesse promover impactos na fauna local, ao competir com espécies nativas por alimento e espaço. Nas florestas, o porco, por ser um animal onívoro, encontra maior variedade de alimentos disponíveis em comparação com os herbívoros bois, cavalos e mulas, criados nas áreas de campos. Comiam de tudo: frutos caídos, sementes, raízes, relva e qualquer animal pequeno (CROSBY, 1993). Para sua criação, existia, por parte da população cabocla, todo um calendário formado pelos ciclos da natureza, regulados pela oferta de frutas locais na primavera e no verão e do pinhão, abundante no outono. Essa alimentação era completada com o milho, cultivado nas "terras de plantar" (BRANDT, 2015).

Por necessitar de pouco manejo, o porco, que era criado "à solta", também conhecido como porco "alçado", consistia na principal fonte de renda, sobretudo para as famílias que não dispunham de ervais ou grandes áreas de campos em suas terras. Marcados por seus proprietários com diferentes cortes nas orelhas, os animais possuíam uma ampla mobilidade, compartilhando em comum terras de diferentes criadores em busca de alimento, pelo 
fato destas não possuírem cercas - e isso persistiu até a colonização -, "uma vez que a amplitude de terras o dispensava", como aponta Arlene Renk (2004, p. 28). As divisas entre posses ou propriedades legalizadas consistiam em marcos naturais, como córregos, rios ou mesmo árvores marcadas a facão.

Os animais poderiam ser destinados tanto à subsistência das famílias quanto à comercialização. Após a captura, os animais eram confinados em uma encerra de milharal aberta em meio à floresta para continuar a engorda, ou em um mangueirão cercado para impedir a invasão dos animais soltos (QUEIROZ, 1981; CORREA, 1970). Seguiam, então, para a venda em vilas próximas e pequenas fábricas de banha localizadas no Vale do Itajaí, em Porto União ou no Paraná. Com a implementação da Estrada de Ferro São Paulo-Rio Grande, surgiram novos destinos, que poderiam ser as pequenas fábricas de banha e matadouros que se instalaram a partir da colonização nos nascentes núcleos urbanos às margens da ferrovia, ou a comerciantes que os despachavam para Paraná, São Paulo ou Rio Grande do Sul (CORRÊA, 1970; ESPÍNDOLA, 1999).

É possível dizer que esses espaços constituíam o que Sueli Ângelo Furlan (2006, p. 4-5) denomina como uma "floresta cultural". No entender da autora, esta é manejada por populações que usufruem de seus recursos de forma compartilhada, em que se observa o desenvolvimento de práticas condizentes ao ambiente, além de conhecimentos sobre o seu funcionamento e sua utilização de forma sustentável. Eram práticas sociais, espaciais e econômicas efetivadas através de um conjunto de normas e costumes, fundamentadas na tradição e na memória, e que também serviam como uma espécie de delimitação territorial dessas populações (BRANDT; NODARI, 2011). Para a população cabocla, a floresta não representaria "apenas a incidência de uma espécie vegetal ou uma 'mancha' como se diz cartograficamente, mas [também] uma expressão identitária, traduzida por extensões territoriais de pertencimento" (ALMEIDA, 2004, p. 28). Estes espaços foram, contudo, se desagregando e reduzindo, à medida que avançava uma nova dinâmica socioespacial, representada pela apropriação privada da terra, acompanhada pela colonização, cercamento das terras e a exploração madeireira.

\section{Apropriação privada da terra e transformações na paisagem}

Com a Lei de Terras em 1850, as terras devolutas passaram a ser valorizadas de acordo com as terras privadas, o que dificultava o acesso à 
terra por brasileiros pobres ou por imigrantes que aportavam no país desde a segunda década do século XIX (SABOYA, 1995). Essa transformação da terra em mercadoria teve efeitos profundos no processo de ocupação territorial brasileiro, sobretudo a partir da Primeira República, quando as terras devolutas passam ao domínio dos Estados. A política de terras de Santa Catarina, formulada em fins do século XIX, estava direcionada a desenvolver a agricultura e a pecuária, em terras consideradas "desabitadas". Fica evidente, como salienta Paulo Pinheiro Machado (2004, p. 139), "a formulação de uma política de terras ligada ao estímulo da colonização europeia, voltada para o desenvolvimento de uma lavoura comercial - submetida aos interesses de capital mercantil e de empresas particulares especializadas em especulação com terras".

No caso da erva-mate, à medida que essa passava por um processo de mercantilização mais intenso, as terras onde se realizavam tais atividades passavam a ser alvo da apropriação privada, precarizando o acesso à terra e o uso dos ervais em comum pelos caboclos. Em relação à apropriação dos ervais, comenta Maurício Vinhas de Queiroz (1981, p. 64) que "a coleta do mate vinha tendendo a fazer-se cada vez mais e freqüente em terras de propriedade privada". Controlados por coronéis, nesse caso uma referência ao "chefe local" (MONTEIRO, 1974), o Estado concedia a estes e seus apaniguados terras devolutas ricas em ervais. Nesse processo eram frequentes as expulsões violentas de posseiros que viviam ou usufruíam dessas terras. Além da apropriação, a concessão para exploração dos ervais pelo Estado aos coronéis, era outro expediente que coibia a coleta da planta nessas terras pelos moradores locais (QUEIROZ, 1981; CAVALLAZZI, 2003).

Para diversas famílias caboclas que viviam sob o regime da posse, em áreas até então marginais à economia pastoril predominante nos campos, essa política foi experimentada como sendo o início da intensificação de um processo de transformações socioespaciais relacionadas principalmente à questão da terra. Essa condição deu origem a diversas situações de disputa pela sua posse, sendo a Guerra do Contestado, que ocorreu na região entre os anos de 1912 a 1916, o principal marco de resistência da população cabocla (MACHADO, 2004, p. 139).

Os anos posteriores ao conflito marcam a intensificação da exclusão e da marginalização da população cabocla com a colonização e a exploração madeireira, tornando mais precário o acesso e o uso das florestas também em práticas como a criação de animais "à solta". Cada animal neces- 
sitava, como aponta Roberto Lobato Corrêa (1970, p. 93), de cerca de cinco hectares de floresta. "Ela é, pois, uma atividade de áreas de muito baixa densidade demográfica, e, à medida que o povoamento de colonos progredia, essa atividade afastava-se para áreas mais remotas".

A colonização no oeste catarinense teve início a partir da década de 1920, com a atuação de diversas companhias colonizadoras privadas, colocando, de acordo com Eunice Sueli Nodari (2009, p. 34), "em prática a opção de uma migração dirigida a grupos específicos que se adequassem aos padrões estabelecidos pelo governo estadual e por elas próprias, ou seja, que povoassem e colonizassem a região ordeiramente". Às companhias colonizadoras interessava a venda dessas terras. Se, para o governo, colonização quer dizer povoamento e desenvolvimento de áreas "desabitadas", para uma companhia particular, "quer dizer negócio; ela quer ganhar dinheiro e é certo que ganhará se conseguir uma boa qualidade de terra e também gente de boa qualidade" (WAIBEL, 1949, p. 172). A escolha, por parte dos colonizadores, de "gente de boa qualidade" não incidiu sobre a população cabocla, mas, sim, sobre os teutos e ítalo-brasileiros estabelecidos, ao longo do século XIX, nos núcleos de colonização do Rio Grande do Sul. Quando Léo Waibel (1949, p. 174) escreveu o artigo intitulado Princípios da colonização européia no Sul do Brasil, no final da década de 1940, o processo de colonização da região ainda estava em pleno desenvolvimento, "semeando povoados ao longo das estradas e rios, na direção norte, onde está o sertão desabitado", embora quase todas as terras já houvessem sido apropriadas "por indivíduos ou companhias particulares, que especulam sobre a expansão do povoamento em futuro próximo".

Desconsiderada pelas autoridades públicas, a população cabocla passaria a ser denominada como "intrusa" dessas terras que habitavam, em muitos casos, há mais de uma geração e que agora seriam concedidas e retalhadas para a venda aos colonos. $\mathrm{O}$ avanço das relações de mercado envolvendo a terra passou, a partir de então, a transformar a paisagem através da inserção de atividades socioeconômicas externas. $\mathrm{O}$ costume de se criar "à solta", por exemplo, deu origem aos primeiros atritos. A criação sem cerca promovia a desvalorização das terras próximas aos caboclos, pelo risco de invasão dos animais nas lavouras. Os colonos, ao se instalar nas terras, tratavam de derrubar a floresta para o cultivo, cuja produção era voltada à comercialização de seus produtos, principalmente o trigo e o milho, de forma aberta, mantendo a criação fechada, diferentemente das pe- 
quenas plantações da "roça cabocla", dando origem a diversas situações de tensão, promovidas pela incompatibilidade entre as concepções de uso e acesso à terra de colonos e antigos moradores (BRANDT, 2015).

É possível imaginar que a população cabocla esperasse que os colonos se adaptassem às suas práticas de uso da terra, demonstrando a disposição de se "enquadrarem" de maneira semelhante ao que até então ocorria com a chegada de novos moradores que compartilhavam seus costumes. Porém os colonos "formavam grupos bastante fechados, dentro da sua identidade étnica com suas retóricas, símbolos e rituais através dos quais defendiam a manutenção, e, se necessária, a renegociação das suas práticas socioculturais" (BRANDT; NODARI, 2011). Acrescenta-se a esse elemento o baixo custo da terra, se comparado ao das áreas de colonização gaúchas, o que possibilitava a compra de terras contíguas, permitindo que as famílias permanecessem unidas, o que já não ocorria no Rio Grande do Sul (NODARI, 2009).

A exploração dos recursos madeireiros acompanhou esse processo, sendo, inclusive, um dos objetivos colocados desde o início por algumas empresas colonizadoras. Além das colonizadoras, atuavam também grupos do ramo originários do Rio Grande do Sul ou empresas com capital localmente acumulado. Nas áreas mais próximas ao Rio Uruguai, era o próprio rio que servia como escoadouro da produção, seguindo de lá para a Argentina, enquanto no Vale do Rio do Peixe a ferrovia tornou possível e economicamente viável a instalação de um grande número de serrarias que acompanhavam seu traçado, em virtude da facilidade de escoamento (CESCO, 2004; GOULARTI, 2002; NODARI, 2009).

Se antes o uso da madeira destinava-se principalmente às necessidades locais, geralmente extraída pelos próprios ocupantes da terra ou por serrarias de pequeno porte cuja produção visava o abastecimento local, na construção de casas e galpões, a exploração agora passa a dar-se em um volume muito maior (CARVALHO, 2006). A introdução de máquinas, como motosserras e caminhões para o transporte das toras e tábuas serradas, em substituição a serras e juntas de boi, por exemplo, resultaram na aceleração do processo de transformação da paisagem das florestas. $\mathrm{O}$ aumento na extração significava também o avanço sobre áreas cada vez mais remotas, à medida que escasseavam as madeiras economicamente viáveis próximas à ferrovia.

Esta devastação também seria a responsável por erradicar muitos ervais nativos da região. No início da colonização, famílias de colonos tam- 
bém passaram a explorar o produto, porém o desenvolvimento da produção ervateira em terras argentinas foi o responsável pelo declínio da produção do lado brasileiro. Ervais cultivados a partir de sementes de erva-mate que foram transpostas e cultivadas em território argentino no começo do século XX tornaram a província de Misiones uma das principais produtoras do país a partir da década de 1930, não mais necessitando da importação do produto brasileiro. Entrava assim em declínio a produção ervateira na região, sendo substituída simultaneamente pela atividade madeireira (FERRARI, 2011; GOULARTI FILHO, 2012). Essa madeira que seria comercializada nas regiões mais próximas à fronteira com a Argentina, aproveitando os mesmos circuitos já estruturados pelo fluxo da produção ervateira, passando, do lado catarinense, por Dionísio Cerqueira (FERRARI, 2011).

Essas atividades em pouco mais de três décadas deixaram marcas profundas tanto na paisagem quanto no destino de diversas famílias excluídas do acesso e do uso da floresta e seus recursos. Muitos partiram em busca por novas terras, mais distantes, onde inevitavelmente seriam expulsos novamente, ou passaram a trabalhar como assalariados em alguma serraria ou indústria ervateira local que explorava os ervais remanescentes. A extração da erva-mate era vista pelos colonos e colonizadores como uma atividade inferior, desqualificada, de baixa remuneração, em que o trabalho era, na maioria das vezes, sazonal e itinerante (RENK, 2009). A partir de então, para autores como Arlene Renk (2006, p. 194), a atividade ervateira passou a constituir um ofício étnico: "os produtores de erva-mate são colonos ou fazendeiros; e os extratores, invariavelmente, os caboclos. Neste caso, a extração é naturalizada como atividade de caboclos [...]. O corte da erva é 'só com eles'. 'Eles só fazem isso e só sabem fazer isso'”. Aqueles que ainda conseguiram legalizar ao menos parte da posse, mantiveram algumas práticas de sua cultura, como a lavoura no regime da policultura e da coivara ou a criação de animais, que passaram a ter sua circulação restrita pela formação de lavouras, criados fechados pelas cercas ou chiqueiros, ao modo praticado pelos colonos.

\section{Considerações finais}

A "roça cabocla", envolvia técnicas de manejo da floresta e de seus recursos através da policultura itinerante, extração da erva-mate e a criação 
de animais "à solta", moldando o que pode ser chamado de paisagem cabocla na região. Além de conservar morfologicamente a paisagem florestal, a "roça cabocla" era, como foi visto, uma prática costumeira e uma importante fonte de renda para diversas famílias da região.

A apropriação privada da terra e o posterior avanço da colonização e da exploração madeireira fizeram com que as vastas florestas que predominavam na paisagem passassem por profundas transformações, fragmentando espaços antes usufruídos pela população cabocla em atividades como a criação de animais e o extrativismo. Com a colonização, diferentes concepções de vida, de visões de mundo, de temporalidades e espacialidades, que antes eram independentes, estranhas entre si, passam a coexistir em um mesmo espaço, com incompatíveis formas de apropriação e uso da terra, fragmentando não apenas a paisagem florestal, mas também práticas costumeiras de uso da floresta e de seus recursos naturais.

Às famílias posseiras ou àquelas que não se enquadraram na nova lógica de uso da terra, restaram a marginalização e a exclusão, com seus descendentes passando a compor significativa parcela dos moradores das periferias das cidades da região formadas a partir do crescimento populacional de diversos núcleos coloniais. Sem uma qualificação profissional ou oportunidades de emprego, muitos encontram-se desempregados ou buscam sobreviver com trabalhos temporários, compondo também considerável parte dos acampamentos e assentamentos do MST da região (PERTILE, 2013; RENK, 2009).

Discutir e dar visibilidade a cultura cabocla é fundamental para valorizar as práticas socioespaciais dessa população, bem como seu conhecimento tradicional dos usos da terra e de seus recursos naturais. Esses constituem seu legado material e imaterial para a região.

\section{Referências}

ALMEIDA, Alfredo Wagner Berno de. Terras tradicionalmente ocupadas: processos de territorialização e movimentos sociais. Revista de Estudos Urbanos e Regionais, v. 6, n. 1, p. 9-32, maio, 2004.

ARRUDA, Rinaldo. "Populações tradicionais" e a proteção dos recursos naturais em unidades de conservação. Ambiente \& Sociedade, ano II, n. 05, p. 79-94, 1999.

AURAS, Marli. Guerra do Contestado: a organização da irmandade cabocla. 4. ed. Florianópolis: UFSC, 2001. 
BRANDT, M. • Paisagem e uso comum da Floresta Ombrófila Mista pela população cabocla...

BRANDT, Marlon; NODARI, Eunice Sueli. Comunidades tradicionais da Floresta de Araucária de Santa Catarina: territorialidade e memória. História Unisinos, São Leopoldo, v. 15, n. 1, p. 80-90, 2011.

BRANDT, Marlon; SILVA, Naiara Sampaio. A coleta da erva-mate pela população cabocla do Vale do Rio do Peixe e Oeste de Santa Catarina: apropriação privada da terra e rupturas (décadas de 1900 a 1940). Sociedade e natureza, Uberlândia, v. 26, n. 3, p. 459-469, 2014.

BRANDT, Marlon; SILVA, Naiara Sampaio. Criação de porcos "à solta" na Floresta Ombrófila Mista de Santa Catarina: paisagem e uso comum da terra. História, São Paulo (online), v. 34, p. 303-322, 2015.

CARVALHO, Miguel Mundstock Xavier de. O desmatamento das florestas de araucária e o Médio Vale do Iguaçu: uma história de riqueza madeireira e colonizações. Dissertação (Mestrado em História) - Centro de Filosofia e Ciências Humanas, Universidade Federal de Santa Catarina, Florianópolis, 2006.

CAVALLAZZI, Rosângela Lunardelli. Contestado: tempo do camponês, espaço da propriedade privada. Florianópolis: Fundação Boiteux, 2003.

CESCO, Susana. Desmatamento e Migração no Alto Vale do Rio o Peixe: discussões sobre o "progresso" e transformação ambiental. Dissertação (Mestrado em História), Centro de Filosofia e Ciências Humanas, Universidade Federal de Santa Catarina, Florianópolis, 2004.

CLAVAL, Paul. A paisagem dos geógrafos. In: CORREA, Roberto Lobato; ROSENDAHL, Zeny (Orgs.). Paisagens textos e identidade. Rio de Janeiro: EdUERJ, 2004.

CORREAA, Roberto Lobato. O sudoeste paranaense antes da colonização. Revista Brasileira de Geografia, Rio de Janeiro, n. 1, ano 32, jan./mar., p. 87-98, 1970.

COSTA, Emília Viotti da. Política de terras no Brasil e nos Estados Unidos. In: Da Monarquia à República: momentos decisivos. 7. ed. São Paulo: Unesp, 1999.

CROSBY, Alfred W. Imperialismo ecológico: a expansão biológica da Europa (9001900). São Paulo: Companhia das Letras, 1993.

DEAN, Warren. A ferro e fogo: a história e a devastação da Mata Atlântica. São Paulo: Companhia das Letras, 2004.

DIEGUES, Antônio Carlos. Repensando e recriando as formas de apropriação comum dos espaços e recursos naturais. In: DIEGUES, Antônio Carlos; MOREIRA, André de Castro (Orgs.). Espaços e recursos naturais de uso comum. São Paulo: Nupaub/USP, 2001.

ESPÍNDOLA, Carlos José. As agroindústrias do Brasil: o caso Sadia. Chapecó: Grifos, 1999. 
FERRARI, Maristela. Interações transfronteiriças na zona de fronteira Brasil-Argentina: o Extremo-Oeste de Santa Catarina e Paraná e Província de Misiones (Século XX e XIX). Tese (Doutorado em Geografia) - Centro de Filosofia e Ciências Humanas, Universidade Federal de Santa Catarina, 2011.

FURLAN, Sueli Ângelo. Florestas Culturais: Manejo Sociocultural, Territorialidades e Sustentabilidade. Agrária, São Paulo, n. 3, p. 3-15, 2006.

GOULARTI FILHO, Alcides. Formação econômica de Santa Catarina. Florianópolis: Cidade Futura, 2002.

GOULARTI FILHO, Alcides. Complexo ervateiro e a pequena produção mercantil em Santa Catarina. Diálogos, Maringá, v. 16, n. 1, p. 179-215, jan./abr., 2012.

INSTITUTO BRASILEIRO DE GEOGRAFIA E ESTATÍSTICA. Manual Técnico da Vegetação Brasileira. 2. ed. Rio de Janeiro: Instituto Brasileiro de Geografia e Estatística - IBGE, 2012.

LAGO, Paulo Fernando. Gente da terra catarinense - desenvolvimento e educação ambiental. Florianópolis: UFSC; FCC; Lunardelli; Udesc, 1988.

LEITE, Pedro Furtado; KLEIN, Roberto Miguel. Vegetação. In: FUNDAÇÃO INSTITUTO BRASILEIRO DE GEOGRAFIA E ESTATÍSTICA. Geografia do Brasil: região Sul. V. 2. Rio de Janeiro: IBGE, 1990.

MACHADO, Paulo Pinheiro. Lideranças do Contestado: a formação e a atuação das chefias caboclas (1912-1916). Campinas: Ed. da Unicamp, 2004.

McKEAN, Margaret A.; OSTROM, Elinor. Regimes de propriedade comum em florestas: somente uma relíquia do passado? In: DIEGUES, Antônio Carlos; MOREIRA, André de Castro (Orgs.). Espaços e recursos naturais de uso comum. São Paulo: Nupaub/USP, 2001.

MONTEIRO, Duglas Teixeira. Errantes do novo século. São Paulo: Duas Cidades, 1974.

MORAN, Emilio F. Interações homem-ambiente em ecossistemas florestais: uma introdução. In: MORAN, Emilio F.; OSTROM, Elinor (Orgs.). Ecossistemas florestais: interações homem-ambiente. São Paulo: Editora Senac São Paulo; EdUSP, 2009.

NODARI, Eunice Sueli. Etnicidades renegociadas: práticas socioculturais no Oeste de Santa Catarina. Florianópolis: Editora da UFSC, 2009.

PARANÁ, Sebastião. Chorographia do Paraná. Curitiba: Typ. da Livraria Econômica, 1899.

PERTILE, Noeli. Espacialidade das ações humanas: o trabalho cotidiano na agricultura familiar do Oeste catarinense. In: CAMPOS, Nazareno José de; BRANDT, Marlon; CANCELIER, Janete Webler. O espaço rural de Santa Catarina: novos estudos. Florianópolis: Ed. da UFSC, 2013. 
BRANDT, M. • Paisagem e uso comum da Floresta Ombrófila Mista pela população cabocla...

QUEIROZ, Maurício Vinhas de. Messianismo e conflito social: a Guerra Sertaneja do Contestado,1912-1916. 2. ed. São Paulo: Ática, 1981. (Coleção Ensaios, n. 23).

RENK, Arlene Anélia. Narrativas da diferença. Chapecó: Argos, 2004.

RENK, Arlene Anélia. A luta da erva: um ofício étnico da nação brasileira no oeste catarinense. 2. ed. Chapecó: Argos, 2006.

RENK, Arlene Anélia. Expropriação do campesinato do Oeste catarinense. In: GODOI, Emília Pietrafesa de; MENEZES, Marilda Aparecida de; MARIN, Rosa Acevedo (Orgs.). Diversidade do campesinato: expressões e categorias: construções identitárias e sociabilidades. V. 1 São Paulo: Editora Unesp; Brasília: Núcleo de Estudos Agrários e Desenvolvimento Rural, 2009.

SABOYA, Vilma Elisa Trindade de. A Lei de Terras (1850) e a Política Imperial seus reflexos na Província de Mato Grosso. Revista Brasileira de História, São Paulo, v. 15, n. 30, p. 115-136, 1995.

SANTOS, Milton. Pensando o espaço do homem. 5. ed. São Paulo: EdUSP, 2004.

SANTOS, Milton. A natureza do espaço: técnica e tempo, razão e emoção. 4. ed. São Paulo: EdUSP, 2006.

WAIBEL, Léo. Princípios da colonização européia no Sul do Brasil. Revista Brasileira de Geografia, Rio de Janeiro, v. 12, n. 2, p. 159-222, abr./jun. 1949. 